\title{
Screening strategies for chronic kidney disease in the general population: follow-up of cross sectional health survey
}

\author{
Stein I Hallan, Ketil Dahl, Cecilia M Oien, Diana C Grootendorst, Arne Aasberg, Jostein Holmen, Friedo W Dekker
}

\begin{abstract}
Objective To find an effective screening strategy for detecting patients with chronic kidney disease and to describe the natural course of the disease.

Design Eight year follow-up of a cross sectional health survey (the HUNT II study).

Setting Nord-Trøndelag County, Norway

Participants 65604 people ( $70.6 \%$ of all adults aged $\geq 20$ in the county).

Main outcome measures Incident end stage renal disease (ESRD) and cardiovascular mortality monitored by individual linkage to central registries.

Results 3069/65 604 (4.7\%) people had chronic kidney disease (estimated glomerular filtration rate $<60 \mathrm{ml} / \mathrm{min} / 1.73 \mathrm{~m}^{2}$ ), so we would need to screen 20.6 people $(95 \%$ confidence interval 20.0 to 21.2 ) to identify one case. Restriction of screening to those with hypertension, diabetes, or age $>55$ would identify 93.2\% (92.4\% to $94.0 \%)$ of patients with chronic kidney disease, with a number needed to screen of 8.7 (8.5 to 9.0). Restriction of screening according to guidelines of the United States kidney disease outcomes quality initiative (US KDOQI) gave similar results, but restriction according to the United Kingdom's chronic kidney disease guidelines detected only $60.9 \%$ (59.1\% to $62.8 \%$ ) of cases. Screening only people with previously known diabetes or hypertension detected $44.2 \%$ (42.7\% to $45.7 \%$ ) of all cases, with a number needed to screen of six. During the eight year follow-up only 38 of the 3069 people with chronic kidney disease progressed to end stage renal disease, and the risk was especially low in people without diabetes or hypertension, women, and those aged $\geq 70$ or with a glomerular filtration rate $45-59 \mathrm{ml} / \mathrm{min} / 1.73 \mathrm{~m}^{2}$ at screening. In contrast, there was a high cardiovascular mortality: 3.5, 7.4, and 10.1 deaths per 100 person years among people with a glomerular filtration rate $45-59,30-44$, and $<30 \mathrm{ml} / \mathrm{min} / 1.73$ $\mathrm{m}^{2}$, respectively.

Conclusion Screening people with hypertension, diabetes mellitus, or age $>55$ was the most effective strategy to detect patients with chronic kidney disease, but the risk of end stage renal disease among those detected was low.
\end{abstract}

\section{Introduction}

The incidence of patients with end stage renal disease who need dialysis or transplantation has more than doubled in Europe and the United States during the past two decades. ${ }^{12}$ In addition to being at risk of end stage renal disease, people with chronic kidney disease have an increased risk of cardiovascular death. ${ }^{34}$ Currently, screening for chronic kidney disease is accepted prac- tice only in patients with hypertension or diabetes, ${ }^{5}{ }^{6}$ but more widespread screening is increasingly proposed. ${ }^{78}$ The United Kingdom chronic kidney disease guidelines also recommend at least annual screening of all adults at risk of obstructive kidney disease and those with prevalent cardiovascular diseases, ${ }^{9}$ while the US kidney disease outcomes quality initiative (US KDOQI) guidelines use age $>60$ for additional inclusion. ${ }^{10}$ Both guidelines highlight the risk associated with multisystem diseases and nephrotoxic drugs. Even more wide ranging, the International Society of Nephrology advocates proactive screening for minor renal damage in all patients visiting general practitioners, similar to the screening for high blood pressure or cholesterol concentrations. ${ }^{11}$ All recommendations, however, are based mostly on consensus procedures rather than hard evidence, ${ }^{912}$ and the different screening strategies have not been compared for their ability to detect chronic kidney disease or their efficiency. It has also been assumed that most patients with advanced renal insufficiency (stages 3-5) will eventually require renal replacement therapy, ${ }^{13}$ but the natural course in those with newly detected disease (stages 3-5) is not well described.

We compared strategies for detecting patients with chronic kidney disease and examined the occurrence of end stage renal disease or cardiovascular death in these patients. We used data from the population based Nord-Trøndelag health study (HUNT study), Norway, and assessed different screening models. We also report on progression to end stage renal disease or cardiovascular death over the next eight years.

\section{Methods}

\section{Study sample and design}

During 1995-7, a large scale general health survey was conducted in Nord-Trøndelag County, Norway. ${ }^{14}$ The population is ethnically homogenous ( $97 \%$ white), and the county is fairly representative of Norway regarding geography, economy, industry, age distribution, morbidity, and mortality. ${ }^{15}$ Everyone aged $\geq 20(\mathrm{n}=92939)$ was invited to participate, and $70.6 \%$ did so. The survey comprised an extensive questionnaire and a brief clinical examination, including analysis of serum creatinine concentration in all participants. Three consecutive standardised blood pressure measurements were recorded with the person seated with an automatic oscillometric method (Dinamap 845XT; Criticon, Tampa, FL). Participants were observed to 31 June 2004 or until advancement to end stage renal disease or death by individual linkage to central registries with the unique 11 digit identification number of every Norwegian citizen. All participants gave informed consent. 


\section{Laboratory methods and estimation of glomerular filtration} rate

Participants gave a blood sample, often in the non-fasting state. Fresh serum samples were analysed within two days with the uncompensated rate Jaffe reaction on a Hitachi 911 Autoanalyzer with reagents from Roche (Roche Diagnostics, Germany). For this study we recalibrated the creatinine values to values traceable with isotope dilution mass spectrometry (IDMS) using an equation describing the relation between the Jaffe method and the Roche enzymatic method in our laboratory ${ }^{16}$ :

IDMS serum creatinine $(\mu \mathrm{mol} / \mathrm{l})=-27.4+1.11 \times \mathrm{Jaffe}$ serum creatinine $(\mu \mathrm{mol} / \mathrm{l})$.

We then estimated the glomerular filtration rate with the new re-expressed four variable formula from the modification of diet in renal disease study (MDRD) for IDMS traceable serum creatinine values ${ }^{17}$ :

glomerular filtration rate $=175 \times($ serum creatinine $(\mu \mathrm{mol} / \mathrm{l}) /$ $88.4)^{-1.154} \times$ age $^{-0.203}(\times 0.742$ for women $)(\times 1.212$ for black people $)$.

The Roche enzymatic method was the same as used for recalibrating the original MDRD creatinine values to IDMS level, ${ }^{17}$ and we have previously shown that the formula then gives unbiased estimates of glomerular filtration rate in the general population. ${ }^{16}$

\section{Statistical analysis}

We first assessed the established high risk model of screening only people with previously known diabetes mellitus or treated hypertension. We then evaluated models that included people with other risk factors like higher age groups, obesity, smoking, cardiovascular disease, or family history of hypertension or diabetes. Finally, we assessed screening models proposed by international kidney authorities: a modification of the UK chronic kidney disease guidelines (screening people with diabetes/hypertension/cardiovascular disease/moderate to severe lower urinary tract symptoms/autoimmune disease); a modification of the US KDOQI (kidney disease outcomes quality initiative) guidelines (screening people with diabetes/ hypertension/age $>60$ /autoimmune disease); and the International Society of Nephrology (screening everybody). When appropriate, we used receiver operating characteristics curves (ROC) to find the cut-off with the highest sum of sensitivity and specificity.

We evaluated the strategies as percentage of all patients with chronic kidney disease stage 3-5 (glomerular filtration rate $<60$ $\mathrm{ml} / \mathrm{min} / 1.73 \mathrm{~m}^{2}$ ) and stage $4-5$ (glomerular filtration rate $<30$ $\mathrm{ml} / \mathrm{min} / 1.73 \mathrm{~m}^{2}$ ) in the general population identified with a particular strategy ("detection rate"); percentage of total adult population included for screening; and the number of people we need to screen to find one case. For this we calculated $95 \%$ confidence intervals as the inverse of the $95 \%$ confidence intervals of the prevalence estimates. We evaluated the clinical importance of detecting patients with chronic kidney disease stage 3-5 with Kaplan Meier analysis for survival without end stage renal disease and cardiovascular death. We used Cox proportional hazard regression analysis to evalute the influence of level of glomerular filtration rate, age, sex, diabetes, and hypertension on progression to end stage renal disease among those with chronic kidney disease. We checked for crossover or other nonproportional survival patterns as well as linearity in age, and binary variables were coded as 0 or 1 and ordinal variables were coded as integer values. The participation rate in the HUNT study 1995-7 was age dependent, being highest in those aged $60-69(86 \%)$ and declining towards $50 \%$ in the youngest and the oldest age groups. ${ }^{15}$ For all analyses we weighted data to reflect
Table 1 Baseline characteristics of participants in the HUNT II study by age. Figures are percentages of people unless stated otherwise*

\begin{tabular}{|c|c|c|c|c|}
\hline & $\begin{array}{l}\text { Total }(n=65 \\
604)\end{array}$ & $\begin{array}{l}20-49 \text { years } \\
(\mathrm{n}=33 \text { 947) }\end{array}$ & $\begin{array}{c}50-69 \\
\text { years } \\
(n=20269)\end{array}$ & $\begin{array}{l}\geq 70 \text { years } \\
(n=11388)\end{array}$ \\
\hline Women & 53.2 & 53.1 & 51.8 & 56.2 \\
\hline Education $\geq 12$ years & 29.3 & 41.6 & 17.9 & 8.3 \\
\hline $\begin{array}{l}\text { Family history of hypertension or } \\
\text { diabetes }\end{array}$ & 37.0 & 35.7 & 42.6 & 31.0 \\
\hline Diabetes mellitus & 3.0 & 0.8 & 3.5 & 8.9 \\
\hline $\begin{array}{l}\text { Hypertension needing drug } \\
\text { treatment }\end{array}$ & 11.1 & 2.0 & 16.4 & 29.6 \\
\hline Cardiovascular disease & 7.9 & 0.7 & 9.5 & 27.7 \\
\hline Current smoking & 27.4 & 33.9 & 29.8 & 13.9 \\
\hline Body mass index $>30$ & 16.3 & 12.4 & 20.6 & 22.5 \\
\hline $\begin{array}{l}\text { Mean (SD) systolic blood pressure } \\
(\mathrm{mm} \mathrm{Hg})\end{array}$ & $\begin{array}{l}137.9 \\
(21.8)\end{array}$ & $\begin{array}{l}128.1 \\
(14.9)\end{array}$ & $\begin{array}{l}143.4 \\
(21.0)\end{array}$ & $\begin{array}{l}157.8 \\
(24.2)\end{array}$ \\
\hline $\begin{array}{l}\text { Mean (SD) diastolic blood pressure } \\
(\mathrm{mm} \mathrm{Hg})\end{array}$ & $80.3(12.3)$ & $76.2(10.5)$ & $\begin{array}{l}84.5 \\
(11.7)\end{array}$ & $85.2(13.7)$ \\
\hline Mean (SD) cholesterol (mmol/l) & $5.89(1.26)$ & $5.40(1.09)$ & $\begin{array}{l}6.40 \\
(1.18)\end{array}$ & $6.48(1.29)$ \\
\hline $\begin{array}{l}\text { Mean (SD) HDL cholesterol } \\
(\mathrm{mmol} / \mathrm{l})\end{array}$ & $1.38(0.39)$ & $1.36(0.37)$ & $\begin{array}{l}1.41 \\
(0.41)\end{array}$ & $1.39(0.41)$ \\
\hline Mean (SD) GFR (ml/min/1.73 m²) & $94.6(30.3)$ & $\begin{array}{l}103.8 \\
(21.5)\end{array}$ & $\begin{array}{l}88.9 \\
(23.0)\end{array}$ & $77.2(48.6)$ \\
\hline
\end{tabular}

$\mathrm{HDL}=$ high density lipoprotein; GFR=glomerular filtration rate.

$* \%$ missing data for variables was as follows: smoking $6.7 \%$, education $5.8 \%$, body mass index $1.3 \%,<1 \%$ for all others including GFR ( $0.6 \%$ missing).

the actual population age distribution. We excluded from the analysis participants with missing data and have indicated the numbers included in the different analyses. Statistical analyses were performed with SPSS version 13.0 (SPSS, Chicago, IL).

\section{Results}

Screening models for chronic kidney disease stage 3-5

Glomerular filtration rate could be estimated in 65193 peoplethat is, $99.4 \%$ of the participants. Median age was 49.0 (range $20-103), 3.0 \%$ reported having diabetes mellitus, and $11.1 \%$ were taking medication for hypertension. The prevalence of chronic kidney disease stage 3-5 (glomerular filtration rate $<60$ $\left.\mathrm{ml} / \mathrm{min} / 1.73 \mathrm{~m}^{2}\right)$ was $4.7 \%(\mathrm{n}=3069)$. Table 1 gives further baseline characteristics.

Restriction of screening to everyone with known hypertension or diabetes mellitus identified $44.2 \%$ (95\% confidence $42.7 \%$ to $45.7 \%$ ) of all cases of chronic kidney disease, and 5.9 people (5.7 to 6.2) were screened to find one case. Because this high risk model detected less than half of all cases, we also evaluated screening in people without previously known diabetes or hypertension. In this group, which included the remaining $55.8 \%$ of chronic kidney disease cases, the number needed to screen was 34.6 (33.3 to 36.0) per case, and we considered various selection criteria for improving effectiveness. Figure 1 illustrates that the detection rate started to fall when we increased the age cut off to 50-60 years. Age restriction, however, dramatically reduced the number needed to screen for people without diabetes or hypertension, while the effect was small for those with diabetes or hypertension. Age restriction therefore seemed most relevant for people without diabetes or hypertension, and in this group analysis of receiver operating characteristics curves indicated that maximum sensitivity plus specificity would be achieved by testing those aged $>55$. Table 2 shows the prevalence of chronic kidney disease stratified by glomerular filtration rate, age, diabetes, and hypertension status so that other strategies than those specifically described here can be examined. 

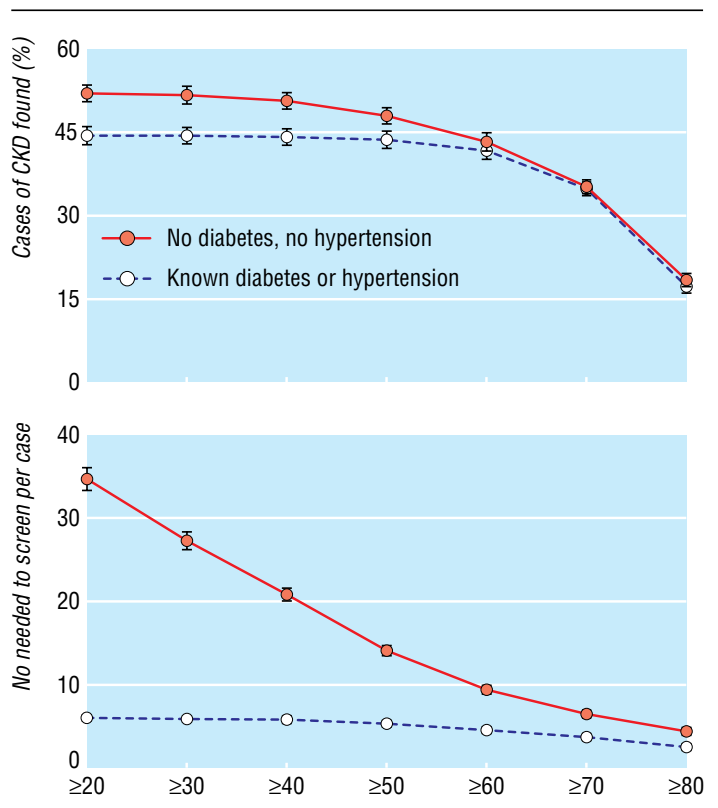

Age groups screened (years)

Fig 1 Effect of age restriction on screening people with $(n=8368)$ and without $(n=56825)$ diabetes or hypertension. Top: proportion of people with chronic kidney disease (CKD) stage 3-5 identified by screening. Bottom: number needed to screen to find one person with chronic kidney disease stage 3-5. Error bars represent $95 \%$ confidence intervals

Table 3 lists effectiveness data for the models evaluated. Extension of screening beyond people with diabetes or hypertension by including other risk factors for chronic kidney disease, such as family history, previous cardiovascular disease, obesity, or smoking, increased the detection rate to $81.4 \%$.The number needed to screen, however, increased significantly to 19.1, and models with a high detection rate and a low number needed to screen are more desirable. Screening that targeted people with hypertension, diabetes, or age $>55$ years identified $93.2 \%(92.4 \%$ to $94.0 \%)$ of cases, and the number needed to screen was 8.7 (8.5 to 9.0). The US guidelines gave similar results. The UK guidelines resulted in a similar number needed to screen but a detection rate of only $60.9 \%(59.1 \%$ to $62.8 \%)$. Theoretically, the International Society of Nephrology's guidelines would identify $100 \%$ of cases, but the number needed to screen was 20.6 (20.0 to 21.2). The ranking of strategies was quite similar with glomerular filtration rate $<30 \mathrm{ml} / \mathrm{min} / 1.73 \mathrm{~m}^{2}$ as outcome, but the number needed to screen was twentyfold higher.

\section{Progression to end stage renal disease or cardiovascular death}

During a median follow-up of 8.0 years (range 0.1-8.9) 51 of 65604 participants progressed to end stage renal disease, and 2604 of 5640 deaths were from cardiovascular disease. Figure 2 highlights the importance of estimated glomerular filtration rate regarding the risk of end stage renal disease. More than $99 \%$ of those with glomerular filtration rate $45-59 \mathrm{ml} / \mathrm{min} / 1.73 \mathrm{~m}^{2}$ were free from end stage renal disease after eight years, and even among those with rate $30-44 \mathrm{ml} / \mathrm{min} / 1.73 \mathrm{~m}^{2} 98 \%$ were free from end stage renal disease. The corresponding proportion among people with glomerular filtration rate $<30 \mathrm{ml} / \mathrm{min} / 1.73$ $\mathrm{m}^{2}$ was only $80 \%$. Incidence rates of end stage renal disease were $0.04,0.2$, and 2.6 per 100 patient years in these groups, respectively. Assumptions for Cox proportional hazard regression analysis were met, and a full analysis of those with glomerular filtration rate $<60 \mathrm{ml} / \mathrm{min} / 1.73 \mathrm{~m}^{2}(\mathrm{n}=3049)$ showed that

Table 2 Prevalence* of chronic kidney disease in general population by age, glomerular filtration rate (GFR) (ml/min/1.73 m²), diabetes, and hypertension

\begin{tabular}{|c|c|c|c|c|c|c|c|c|c|c|c|c|c|c|c|}
\hline \multirow{2}{*}{$\begin{array}{l}\text { Age } \\
\text { (years) }\end{array}$} & \multicolumn{3}{|c|}{ General population } & \multicolumn{3}{|c|}{ Diabetes and hypertension } & \multicolumn{3}{|c|}{ Diabetes, not hypertension } & \multicolumn{3}{|c|}{ Hypertension, not diabetes } & \multicolumn{3}{|c|}{ No diabetes or hypertension } \\
\hline & $45-59$ & $30-44$ & $<30$ & $45-59$ & 30-44 & $<30$ & $45-59$ & 30-44 & $<30$ & $45-59$ & 30-44 & $<30$ & $45-59$ & 30-44 & $<30$ \\
\hline $20-29$ & 0.07 & 0 & 0.02 & 0 & 0 & 0 & 0 & 0 & 0 & 0.1 & 0 & 0.1 & 0.1 & 0 & 0 \\
\hline $30-39$ & 0.26 & 0.02 & 0.01 & 0 & 0 & 0 & 1.6 & 0 & 0 & 0.5 & 0.1 & 0.1 & 0.2 & 0 & 0 \\
\hline $40-49$ & 0.71 & 0.09 & 0.02 & 1.1 & 0 & 0 & 0.0 & 0 & 1.3 & 0.9 & 0.2 & 0 & 0.6 & 0.1 & 0 \\
\hline $50-59$ & 1.81 & 0.22 & 0.03 & 1.2 & 1.2 & 0.4 & 1.3 & 1.3 & 0 & 2.1 & 0.3 & 0.1 & 1.6 & 0.2 & 0 \\
\hline $60-69$ & 5.23 & 0.90 & 0.28 & 7.3 & 2.9 & 0.5 & 7.7 & 0.0 & 0 & 5.5 & 1.0 & 0.3 & 4.1 & 0.3 & 0.2 \\
\hline $70-79$ & 11.71 & 2.68 & 0.37 & 13.9 & 3.9 & 1.4 & 13.8 & 2.3 & 0 & 12.4 & 2.7 & 0.3 & 7.8 & 1.9 & 0.3 \\
\hline $80-89$ & 19.82 & 6.15 & 1.73 & 19.3 & 10.0 & 2.7 & 30.2 & 14.0 & 2.3 & 20.3 & 5.3 & 1.3 & 15.7 & 4.7 & 1.5 \\
\hline$\geq 90$ & 25.00 & 13.49 & 3.17 & 25.0 & 8.3 & 0 & 0 & 0 & 0 & 26.5 & 12.1 & 0.8 & 25.9 & 7.4 & 11.1 \\
\hline
\end{tabular}

${ }^{*}$ Given as \%. Number needed to screen can be calculated as $1 /($ prevalence in \%/100). For example, among people aged 60-69 from general population we need to screen $1 /(5.23 / 100)=19.1$ to find one person with GFR $45-59 \mathrm{ml} / \mathrm{min} / 1.73 \mathrm{~m}^{2}$.

Table 3 Effectiveness of different screening strategies for detecting people with chronic kidney disease (CKD)

\begin{tabular}{|c|c|c|c|c|c|c|}
\hline \multirow{2}{*}{ Screening strategy } & \multicolumn{3}{|c|}{ CKD stage $3-5\left(\right.$ GFR $\left.<60 \mathrm{ml} / \mathrm{min} / 1.73 \mathrm{~m}^{2}\right)$} & \multicolumn{3}{|c|}{ CKD stage 4-5 (GFR <30 ml/min/1.73 $\left.\mathrm{m}^{2}\right)$} \\
\hline & $\%$ found ${ }^{*}$ & $\%$ included $\dagger$ & NNTSł $(95 \% \mathrm{Cl})$ & $\%$ found ${ }^{*}$ & $\%$ included & NNTS $\ddagger(95 \% \mathrm{Cl})$ \\
\hline$\overline{\mathrm{DM} / \mathrm{HT}}$ & 44.2 & 12.0 & 5.9 (5.7 to 6.2$)$ & 53.9 & 12.0 & 124 (101 to 153) \\
\hline DM/HT/family§ & 59.8 & 41.8 & 15.3 (14.8 to 15.9$)$ & 63.6 & 41.8 & 368 (304 to 445) \\
\hline $\mathrm{DM} / \mathrm{HT} / \mathrm{CVD}$ & 57.5 & 16.0 & $6.1(5.9$ to 6.3$)$ & 73.8 & 16.0 & 122 (102 to 145$)$ \\
\hline DM/HT/CVD/obesity/smoking & 73.8 & 50.0 & 15.8 (15.2 to 16.3$)$ & 86.5 & 50.0 & 389 (323 to 470$)$ \\
\hline$\overline{\mathrm{DM} / \mathrm{HT} / \mathrm{CVD} / \text { obesity/smoking/family§ }}$ & 81.4 & 66.9 & 19.1 (18.5 to 19.8$)$ & 90.5 & 66.9 & 499 (415 to 599) \\
\hline $\mathrm{DM} / \mathrm{HT} />55$ & 93.2 & 37.1 & 8.7 (8.5 to 9.0) & 98.2 & 37.1 & 211 (181 to 246) \\
\hline UK CKD guidelines & 60.9 & 19.9 & $8.6(8.2$ to 9.0$)$ & 84.4 & 19.9 & 174 (140 to 217) \\
\hline US KDOQI guidelines & 89.3 & 29.0 & 8.7 (8.4 to 9.0) & 97.5 & 29.0 & 201 (168 to 240) \\
\hline ISN guidelines (everybody) & 100.0 & 100.0 & 20.6 (20.0 to 21.2) & 100.0 & 100.0 & 467 (407 to 536) \\
\hline
\end{tabular}

GFR=glomerular filtration rate; DM=diabetes mellitus; $H T=$ hypertension; $C V D=$ cardiovascular disease; KDOQI=kidney disease outcomes quality initiative; ISN=International Society of Nephrology.

*Proportion of valid cases with GFR $<60 \mathrm{ml} / \mathrm{min} / 1.73 \mathrm{~m}^{2}$ or GFR $<30 \mathrm{ml} / \mathrm{min} / 1.73 \mathrm{~m}^{2}$ from the HUNT II cohort detected with screening strategy.

†Proportion of valid subjects selected for screening with strategy.

† Number needed to screen to find one case.

$\S$ First degree relative with hypertension or diabetes. 

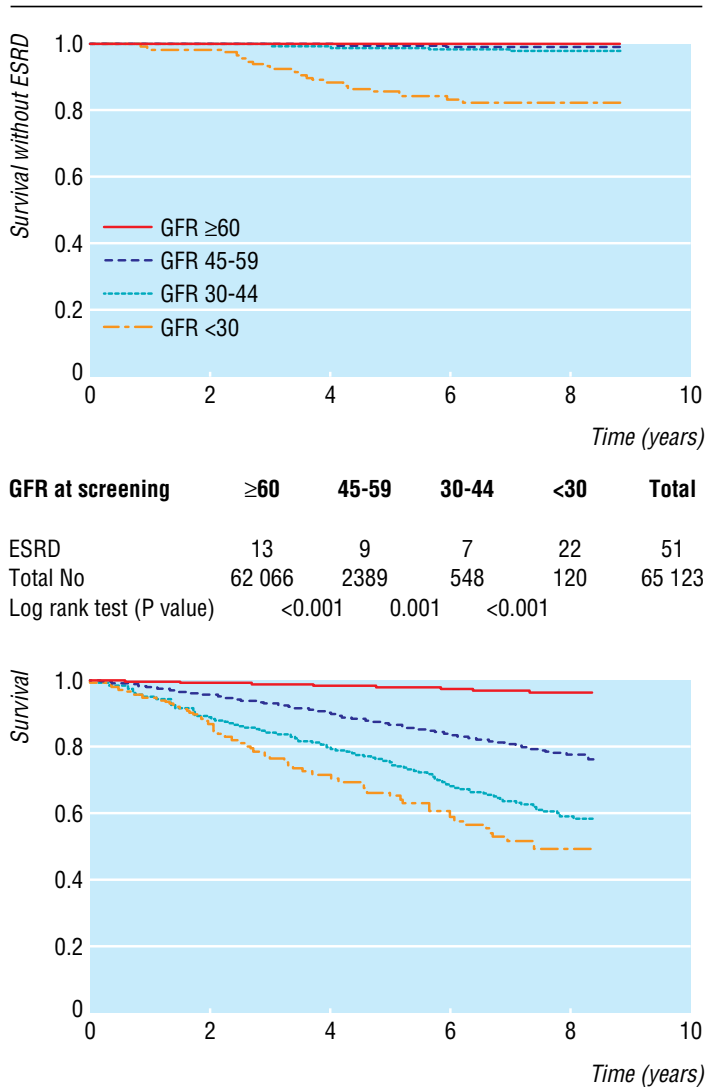

$\begin{array}{lccccc}\text { GFR at screening } & \geq \mathbf{6 0} & \mathbf{4 5 - 5 9} & \mathbf{3 0 - 4 4} & <\mathbf{3 0} & \text { Total } \\ & & & & & \\ \text { Cardiovascular death } & 1913 & 456 & 185 & 50 & 2604 \\ \text { Total No } & 62099 & 2389 & 548 & 120 & 65156 \\ \text { Log rank test (P value) } & <0.001 \quad<0.001 & 0.035 & \end{array}$

Fig 2 Survival without end stage renal disease (ESRD) and cardiovascular death by glomerular filtration rate (GFR) $\left(\mathrm{ml} / \mathrm{min} / 1.73 \mathrm{~m}^{2}\right)$ at screening

the risk of progression to end stage renal disease was influenced by several variables: glomerular filtration rate was of major importance (hazard ratio 1.0 for rate $45-59 ; 4.2$ (1.5 to 11 ) for rate $30-44 ; 68.5$ (30 to 156 ) for rate $<30 \mathrm{ml} / \mathrm{min} / 1.73 \mathrm{~m}^{2}$ ), but there was also an increased risk in men (3.2 (1.6 to 6.4)), in people aged $<70$ years $(5.7(2.8$ to 11$))$, and in those with diabetes or hypertension (3.1 (0.98 to 10)). Smoking, body mass index, and prevalent cardiovascular disease were not of significance.

Figure 2 also shows risk of cardiovascular death at different glomerular filtration rates. Cardiovascular death accounted for $56 \%$ of the total number of deaths among people with chronic kidney disease compared with $44 \%$ in those without chronic kidney disease. Cardiovascular mortality among those without chronic kidney disease was 0.4 per 100 person years. Mortality, however, was much higher among people with chronic kidney disease and increased with decreasing glomerular filtration rate: 3.5 for rate $45-59,7.4$ for rate $30-44$, and 10.1 for rate $<30$ $\mathrm{ml} / \mathrm{min} / 1.73 \mathrm{~m}^{2}$.

\section{Discussion}

A high risk screening model targeting only those with diabetes or hypertension would identify less than half of those with chronic kidney disease. A model that also targeted those aged $>55$ would identify $93 \%$, with only a few more people needed to screen than for the high risk strategy (nine versus six per case).
The incidence rate of end stage renal disease was low among people with glomerular filtration rate $30-60 \mathrm{ml} / \mathrm{min} / 1.73 \mathrm{~m}^{2}$ at screening, while cardiovascular mortality was much higher $(0.1$ and 4.2 per 100 person years, respectively). Cases with glomerular filtration rate $<30 \mathrm{ml} / \mathrm{min} / 1.73 \mathrm{~m}^{2}$ had a high risk for both outcomes (incidence of end stage renal disease 2.6 and cardiovascular mortality 10.1 per 100 person years).

\section{Strengths and weaknesses of the study}

Our use of death certificates to ascertain cause of death and reliance on one creatinine measurement might have led to misclassification. We had no data on the effect of intervention or costs of screening and follow-up. We did not know how many prevalent cases of chronic kidney disease were already known to the health services, but studies from several countries indicate that the number is low (5-25\%). ${ }^{18-21}$ Our study, however, was based on data from a large survey with a high participation rate. We minimised the risk of underestimating glomerular filtration rate by thorough adjustment of serum creatinine values. ${ }^{22}$ Linkage to central registries for information on renal replacement therapy and mortality was possible in all cases. Annual cross checking against the productions data of all dialysis units throughout the country has shown that the Norwegian Renal Registry is more than $99 \%$ complete (T Leivestad, director of the renal registry, personal communication). Cause of death is available in $99.6 \%$ of people at the death registry of Statistics Norway. ${ }^{15}$ The dataset was therefore suitable for illustrating various models for screening strategies, but comprehensive cost effectiveness studies are needed to show whether screening is justified or not. The optimal screening interval also remains to be found.

\section{Comparison of strategies}

We are aware of only one other study reporting on the performance of similar screening strategies. ${ }^{23}$ The kidney early evaluation project (KEEP) reported that seven people with diabetes or hypertension or with first degree relatives with diabetes, hypertension, or kidney disease need to be screened for one case of chronic kidney disease to be found. This is in contrast with our results as we found that we needed to screen 15 people when we used similar criteria. Other risk factors, however, such as obesity and African descent are more prevalent in the US. Effectiveness of strategies targeting high risk subgroups could therefore be different, and such strategies could be more suitable in high risk populations as in the US. A significant proportion of patients, however, could still escape detection.

Few evidence based studies can help in selecting the optimal screening strategy. In an extensive cost effectiveness analysis of screening for proteinuria in US adults, Boulware et al showed that maximising sensitivity was more important than maximising specificity. ${ }^{24}$ According to this, the US guidelines or the simple strategy of targeting people with diabetes, hypertension, or age $>55$ would be good choices. The UK guidelines, which do not use age as a risk factor, detect far fewer cases. Although the risk for progression to end stage renal disease is lower among the people $>70$ years, the UK strategy would miss many people in the age range 55-75 who could benefit from active intervention.

Our data show that progression to end stage renal disease among patients with chronic kidney disease stage 3-5 is rare, contrary to the previous assumption that most of these patients will eventually require renal replacement treatment. ${ }^{13}$ A nationwide population based cohort study in Sweden found that $80 \%$ of patients with renal failure progressed to end stage renal disease within five years. ${ }^{25}$ The inclusion criterion, however, was serum creatinine $>300 \mu \mathrm{mol} / 1(250 \mu \mathrm{mol} / \mathrm{l}$ in women $)$, which roughly corresponds to a glomerular filtration rate of $<20$ 
$\mathrm{ml} / \mathrm{min} / 1.73 \mathrm{~m}^{2}$ for most people included. Other studies have found that $4 \%$ of incident cases $^{26}$ and $2.5 \%$ of prevalent cases ${ }^{27}$ with glomerular filtration rate $<60 \mathrm{ml} / \mathrm{min} / 1.73 \mathrm{~m}^{2}$ progress to end stage renal disease in five years. The lower risk in our study may be explained by the inclusion of truly unselected cases, while other studies included individuals seeking medical advice.

\section{Health policy and clinical implications}

There is concern about the growing agenda of risk and prevention. ${ }^{28}{ }^{29}$ For screening for chronic kidney disease, there is lack of information on several aspects of the World Health Organization's criteria for a screening programme ${ }^{30}$ Clearly, chronic kidney disease is an important problem with a recognisable preclinical phase, suitable tests acceptable to the population are available, and numerous studies have shown that various forms of treatment can delay the onset of end stage renal disease $\mathrm{e}^{31-36}$ and reduce cardiovascular complications, which is equally important as it benefits many more patients. ${ }^{37}$ Not enough is known about the natural course of the condition and the acceptance and effectiveness of the screening test. Efficient screening might lead to an increase in workload for the health services as the patients detected are at high risk and need intensive intervention to prevent progression to end stage renal disease and cardiovascular complications. The costs of detecting patients and treating them might not be economically balanced in relation to possible expenditure on medical care as a whole.

We cannot address all of these aspects or conclude whether screening should be performed or not. We can, however, provide important information for policy makers regarding strategies for detecting chronic kidney disease and the natural course in patients. The former is important as we have shown that finding cases of chronic kidney disease can be done effectively. The latter is important because most patients with a glomerular filtration rate of $30-60 \mathrm{ml} / \mathrm{min} / 1.73 \mathrm{~m}^{2}$ at screening had a low incidence of end stage renal disease, at least in the first eight years, while their risk of cardiovascular mortality was high. This could be important for planning an optimal follow-up.

In practice, patients with chronic kidney disease would be best managed in partnership between primary and secondary care $^{38}$ When glomerular filtration rate has fallen to $\leq 30$ $\mathrm{ml} / \mathrm{min} / 1.73 \mathrm{~m}^{2}$ the time till end stage renal disease is short, irrespective of other risk factors like sex, diabetes, hypertension, and albuminuria. These patients should be referred to a nephrologist as most of them will need correction of anaemia, nutritional status, bone disease, etc, and many must also start preparation for renal replacement. Patients with a glomerular filtration rate of $30-60 \mathrm{ml} / \mathrm{min} / 1.73 \mathrm{~m}^{2}$ have a much lower incidence rate of end stage renal disease and could probably be managed by their general practitioner or in collaboration with a nephrologist if there is progression or other problems like anaemia, electrolyte disturbances, or non-optimal control of diabetes or blood pressure. Special attention must be paid to patients with diabetes or hypertension with albuminuria, but all need follow-up for prevention of cardiovascular complications.

The HUNT study is a collaboration between HUNT Research Center, Faculty of Medicine, Norwegian University of Science and Technology, Verdal; Norwegian Institute of Public Health, Oslo; Nord-Trondelag County Council; and Central Norway Regional Health Authority. We thank the health service and people of Nord-Trondelag for their endurance and participation and Stephen Lock for his help in preparing the manuscript. Contributors: $\mathrm{SIH}$ (guarantor), JH, and $\mathrm{KD}$ were responsible for conception and design. SIH, FWD, DCG, AA, and CMO analysed and interpreted the data. SIH drafted the article and FWD, DCG, KD, CMO, AA, and JH revised it. JH was in charge of the data collection during the HUNT study.
Funding: KD and AA are employed at St Olav's Hospital. SIH, CMO, and JH are funded by Norwegian University of Science and Technology. FWD and DCG are funded by Leiden University.

Competing interests: None declared.

Ethical approval: Regional committee for medical research ethics, health region 4, Norway. Additional permission for linking data registries and for handling the health data was given by the Health Department and by the Data Inspectorate, respectively.

1 van Dijk PC, Jager KJ, de Charro F, Collart F, Cornet R, Dekker FW, et al. Renal replacement therapy in Europe: the results of a collaborative effort by the ERA-EDTA registry and six national or regional registries. Nephrol Dial Transplant 2001;16:1120-9.

2 US Renal Data System/National Institutes of Health. Annual data report: atlas of end-stage renal disease in the United States. 2003. www.usrds.org/adr.htm (accessed May 2004)

3 Go AS, Chertow GM, Fan D, McCulloch CE, Hsu CY. Chronic kidney disease and the risks of death, cardiovascular events, and hospitalization. N Engl J Med 2004;351:1296305 .

4 Henry RM, Kostense PJ, Bos G, Dekker JM, Nijpels G, Heine RJ, et al. Mild renal insufficiency is associated with increased cardiovascular mortality: the Hoorn study. Kidney Int 2002;62:1402-7.

5 Williams B, Poulter NR, Brown MJ, Davis M, McInnes GT, Potter JF, et al. British Hypertension Society guidelines for hypertension management 2004 (BHS-IV): summary. BMJ 2004;328:634-40.

6 American Diabetes Association. Standards of medical care in diabetes-2006. Diabetes American Diabetes Care 2006;29:S4-42.

7 Remuzzi G, Weening JJ. Albuminuria as early test for vascular disease. Lancet 2005;365:556-7.

8 de Jong PE, Brenner BM. From secondary to primary prevention of progressive renal disease: the case for screening for albuminuria. Kidney Int 2004;66:2109-18.

9 Chronic kidney disease in adults: UK guidelines for identification, management and referral of adults. www.renal.org/CKDguide (assessed Dec 2005).

$10 \mathrm{~K} / \mathrm{DOQI}$ clinical practice guidelines for chronic kidney disease: evaluation, classification, and stratification. Kidney disease outcome quality initiative. Am J Kidney Dis 2002;39:S1-246.

11 International Society of Nephrology. ISN calls for proactive albuminuria testing. ISN News 2005;13:3.

12 McClellan WM, Ramirez SP, Jurkovitz C. Screening for chronic kidney disease: unresolved issues. JAm Soc Nephrol 2003;14:S81-7.

13 Nahas ME. The global challenge of chronic kidney disease. Kidney Int 2005;68:2918-29. 14 Holmen J, Midthjell K, Kruger O, Langhammer A, Lingaas Holmen T, Bratberg G, et al. The Nord-Trondelag health study 1995-97 (HUNT 2): objectives, contents, methods and participation. Norsk Epidemiologi 2003;13:19-32

15 Statistics Norway. www.ssb.no (accessed May 2004).

16 Hallan S, Astor BC, Lydersen S. Estimating glomerular filtration rate in the general population: the second health survey of Nord Trondelag (HUNT II). Nephrol Dial Transplant 2006;21:1525-33.

17 Levey AS, Coresh J, Greene T, Marsh J, Stevens L, Kusek J, et al. Expressing the MDRD study equation for estimating GFR with IDMS traceable (gold standard) serum creatistudy equation for estimating GFR with IDMS traceable
nine values (Abstract). J Am Soc Nephrol 2005;11:16:69A.

18 Coresh J, Byrd-Holt D, Astor BC, Briggs JP, Eggers PW, Lacher DA, et al. Chronic kidney disease awareness, prevalence, and trends among US adults, 1999 to 2000. J Am Soc Nephrol 2005;16:180-8.

19 de Lusignan S, Chan T, Stevens P, O’Donoghue D, Hague N, Dzregah B, et al. Identifying patients with chronic kidney disease from general practice computer records. Fam Pract 2005;22:234-41.

\section{What is already known on this topic}

Knowledge of the disease, the test, and effectiveness are important for screening programmes, but this information is partly missing for chronic kidney disease

Currently, screening for chronic kidney disease is established for patients with hypertension or diabetes, but UK and US guidelines recommend expanding these criteria

\section{What this study adds}

A simple screening strategy targeting people with diabetes, hypertension, or age $>55$ had the highest detection rate for chronic kidney disease combined with a low number needed to screen

Most patients detected had a low risk of progression to end stage renal disease

Whether screening is cost effective needs further research, and extending screening to people without diabetes or hypertension cannot yet be recommended 
20 John R, Webb M, Young A, Stevens PE. Unreferred chronic kidney disease: a longitudihal study. Am J Kidney Dis 2004:43:825-35.

21 Stevens LA, Fares G, Fleming J, Martin D, Murthy K, Qiu J, et al. Low rates of testing and diagnostic codes usage in a commercial clinical laboratory: evidence for lack of physician awareness of chronic kidney disease. J Am Soc Nephrol 2005;16:2439-48.

22 Coresh J, Astor BC, McQuillan G, Kusek J, Greene T, Van Lente F, et al. Calibration and random variation of the serum creatinine assay as critical elements of using equations to estimate glomerular filtration rate. Am J Kidney Dis 2002;39:920-9.

23 Brown WW, Peters RM, Ohmit SE, Keane WF, Collins A, Chen SC, et al. Early detection of kidney disease in community settings: the kidney early evaluation program (KEEP). Am J Kidney Dis 2003;14:22-35.

24 Boulware LE, Jaar BG, Tarver-Carr ME, Brancati FL, Powe NR. Screening for proteinuria in US adults: a cost-effectiveness analysis. JAMA 2003;17:3101-14

25 Evans M, Fryzek JP, Elinder CG, Cohen SS, McLaughlin JK, Nyren O, et al. The natural history of chronic renal failure: results from an unselected, population-based, inception cohort in Sweden. Am J Kidney Dis 2005;46:863-70.

26 Drey N, Roderick P, Mullee M, Rogerson M. A population-based study of the incidence and outcomes of diagnosed chronic kidney disease. Am J Kidney Dis 2003;42:677-84.

27 Keith DS, Nichols GA, Gullion CM, Brown JB, Smith DH. Longitudinal follow-up and outcomes among a population with chronic kidney disease in a large managed care organization. Arch Intern Med 2004;164:659-63.

28 Westin S, Heath I. Thresholds for normal blood pressure and serum cholesterol. BMJ 2005;330:1461-2.

29 Getz L, Sigurdsson JA, Hetlevik I. Is opportunistic disease prevention in the consultation ethically justifiable? BMJ 2003;327:498-500.

30 Wilson JM, Jungner G. Principles and practice of screening for disease. Geneva: World Health Organization, 1968.

31 Gouva C, Nikolopoulos P, Ioannidis JP, Siamopoulos KC. Treating anemia early in renal failure patients slows the decline of renal function: a randomized controlled trial. Kidney Int 2004;66:753-60.

32 Fried LF, Orchard TJ, Kasiske BL. Effect of lipid reduction on the progression of renal disease: a meta-analysis. Kidney Int 2001;59:260-9.

33 Jafar TH, Stark PC, Schmid CH, Landa M, Maschio G, de Jong PE, et al. Progression of chronic kidney disease: the role of blood pressure control, proteinuria, and angiotensin-converting enzyme inhibition: a patient-level meta-analysis. Ann Intern Med angiotensin-converting enzyme inhibiton. a patient-level meta-analysis. Arn Tmien Med

34 Maki DD, Ma JZ, Louis TA, Kasiske BL. Long-term effects of antihypertensive agents on proteinuria and renal function. Arch Intern Med 1995;155:1073-80.

35 Pedrini MT, Levey AS, Lau J, Chalmers TC, Wang PH. The effect of dietary protein restriction on the progression of diabetic and nondiabetic renal diseases: a meta-analysis. Ann Intern Med 1996;124:627-32.

36 Wang PH, Lau J, Chalmers TC. Metaanalysis of the effects of intensive glycemic control on late complications of type I diabetes mellitus. Online J Curr Clin Trials 1993;Doc No 60.

37 Powe NR. Early referral in chronic kidney disease: an enormous opportunity for prevention. Am J Kidney Dis 2003;41:505-7.
38 Frankel A, Brown E, Wingfield D. Management of chronic kidney disease. BMJ 2005;330:1039-40.

(Accepted 14 September 2006)

doi 10.1136/bmj.39001.657755.BE

Department of Cancer Research and Molecular Biology, Faculty of Medicine, Norwegian University of Science and Technology, 7006 Trondheim, Norway Stein I Hallan associate professor

Department of Medicine, Division of Nephrology, St Olav University Hospital, 7006 Trondheim, Norway

Ketil Dahl consultant

Cecilia M Oien consultant

Department of Clinical Epidemiology, Leiden University Medical Center, 2300 Leiden, Netherlands

Diana C Grootendorst postdoctoral fellow

Friedo W Dekker associate professor

Department of Clinical Biochemistry, St Olav University Hospital, 7006 Trondheim, Norway

Arne Aasberg consultant

HUNT Research Center, Faculty of Medicine, Norwegian University of Science and Technology, 7650 Verdal, Norway

Jostein Holmen professor

Correspondence to: S I Hallan stein.hallan@ntnu.no

This is version 3 of the paper. Due to an error in the analysis the figures given for the UK chronic kidney disease guidelines in the abstract, results section, and table 3 were incorrect. These have been amended. The changes do not have any effect on the conclusions of the paper. 